\title{
SPC AND CREEP AND TESTS OF TYPE F MODIFIED CHROMIUM STEEL
}

\author{
'Zdeněk KUBOŇ, ${ }^{2}$ Josef KASL \\ ${ }^{1}$ MATERIAL AND METALLURGICAL RESEARCH Ltd., Ostrava, Czech Republic, EU, \\ zdenek.kubon@mmvyzkum.cz \\ ${ }^{2}$ Research and Testing Institute Pilsen, Pilsen, Czech Republic, EU, kasl@vzuplzen.cz
}

https://doi.org/10.37904/metal.2019.837

\begin{abstract}
Small punch creep test (SPC) is an alternative method for obtaining information about the material properties of steels and alloys when only a limited amount of test material is available that does not make it possible to perform conventional creep and/or stress rupture tests. SPCT testing can also be used for determination of the residual life of critical components of a fossil fuelled power plant. SPCT method is a part of the CWA 15627 "Small Punch Test Method for Metallic Materials" published in 2007 and this method will be a part of a prepared proposal of a standard of Small Punch Testing. Similar activities are also within ASTM (ASTM WK47431 "New Practice for Small Punch Test Method for Metallic Materials"), and in Japan they have an approved SPCT test standard. Although the complex stress state of the SPCT tests differs considerably from the uniaxial tension in case of creep test and further changes during the test, it was shown that the same stress-temperature dependence and relationships are valid in SPCT tests as in creep tests, and by using a simple load-based conversion factor between the SPCT test and the creep test with the same time to rupture, the results of both test types can be integrated. This is demonstrated by an example of modified chromium steel of F-type where a comparison of creep and SPCT tests results was presented, as well as the conversion factor that allows comparison of these two methods.
\end{abstract}

Keywords: Creep; SPC; modified chromium steel; extrapolation methods; creep rupture strength

\section{INTRODUCTION}

The small punch testing method is still an innovative and very perspective way of determining material characteristics, especially when it is not possible to use conventional test methods, either because of the lack of test material or the impossibility, technical difficulty or economic disadvantage of its sampling, which often occurs in the case of already operated components. The method was originally developed about three decades ago as a method of sampling and evaluating the degradation of pressure vessel materials and nuclear power plant reactors, where the size of the specimen plays an important role in terms of radioactivity. The method has rapidly spread to other areas, especially conventional power engineering, heavy chemistry and also general engineering, and now it is considered to be an effective tool for assessment of the actual material properties of steels and alloys. It has been successfully used to determine mechanical properties (yield strength, ultimate tensile strength), notch toughness (FATT transition temperature), fracture toughness, lowcycle fatigue and creep [1-3]. The small punch testing method usually requires only a small amount of testing material, but it can provide key information on material properties, e. g. of special areas, such as determining the creep resistance of the heat-affected area of welded joints [4]. Recently, small punch creep tests (SPC tests) have been appraised for their unique potential for material properties evaluation of new aircraft materials where there is usually not enough material for a conventional testing [5]. The biggest advantage of the SPC tests is that they can also be used in the assessment of the residual life of long-term creep exposed power plant components, where test material can be sampled even from critical sites of the structure without the necessity of any repair.

The presented paper describes the principle of the SPC testing method, its correlation with conventional creep tests and the results obtained in testing creep properties of the advanced chromium modified steel $\mathrm{F}$. 


\section{SMALL PUNCH CREEP TESTS}

Small punch creep test is the one of the small punch testing methods applied in creep conditions, when a small punch - usually a ceramic ball - penetrates under a constant-force through the disc supported by a ring (Figure 1), and the time dependence of the deflection in the centre of the specimen is recorded. The test is finished by the perforation of the specimen and the time to failure and final deflection is recorded after the test. The testing cartridge is placed in an argon shielded furnace that prevents high temperature oxidation of the sample.



Figure 1 Scheme of SPC test cartridge

In Europe, a program of comprehensive evaluation of creep properties by SPC testing was launched within the COPERNICUS project, which took place in the early 1990s, and at present time many research teams devote themselves to this innovative method of creep testing. Specifically, the applicability of SPC testing in the determination of the activation energy of creep and the application of the Monkman-Grant equation, which describes the relationship between the time to fracture and the minimum creep rate, was demonstrated. Furthermore, simple empirical relationships between SPCT and conventional creep tests have been developed [6]. Although, unlike the uniaxial creep test, SPC has a complex interaction between material and punch (ball), it is also possible to find three typical stages of a creep curve, i.e. primary, secondary and tertiary creep stage (Figure 2).

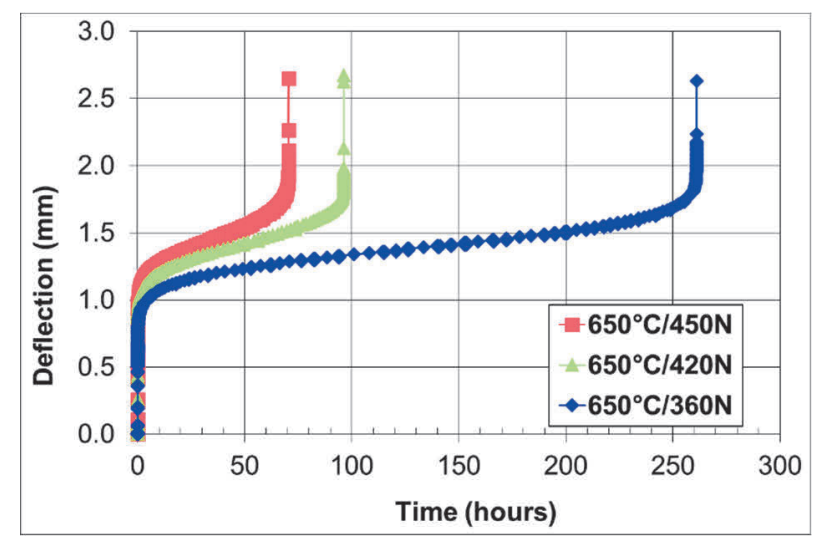

Figure 2 Small punch creep curves of steel $\mathrm{F}$

In a conventional uniaxial creep test the principal testing parameters are temperature and stress, whilst in the SPC test the only load is known, as stress changes during the test. In order to interpret the results of SPC tests it is necessary to establish a correlation between the load $F$ and the stress $\sigma$. The theoretical derivation of the relation between the load and its corresponding stress during SPC test is based on the work of Chakrabarty [7], who studied the deflection of a thin, firmly clamped membrane caused by the movement of a punch with a round head. The relationship between load $F$ and membrane stress $\sigma$ as a function of the specimen thickness $h$, the specimen radius $r$ and the contact angle $\theta$ between the punch and the sample can be expressed in the form [8]: 
$\frac{F}{\sigma}=2 \pi \cdot h \cdot r \cdot \sin ^{2} \theta_{0}$

For the SPC testing the equation (1) was adapted into the form:

$\frac{F}{\sigma}=3.33 \cdot k_{S P} \cdot R^{-0.2} \cdot r^{1.2} h_{0}$

where $h_{0}$ is the original specimen thickness, $R$ is the radius of the receiving hole, and $k_{S P}$ is a constant describing the material plasticity.

However, the practical evaluation of SPC results is usually based on correlation between results of the conventional uniaxial creep tests and SPC tests. Such a correlation compares load of SPC test and stress of the uniaxial creep tests for the same temperature and time to rupture. In a simplified form and for identical sample thickness, the relationship (2) takes the form:

$\frac{F}{\sigma}=\Psi$

The value of the constant $\Psi$ in this equation is usually in the range of about 1.2 to 2.5 for most steels.

The creep test results can be mathematically expressed in the form of Norton's equation for time to rupture (4) and the similar equation can be also used for the load dependence of time to rupture in SPC tests:

$t_{r}=A_{c r} \cdot \sigma^{-n_{c r}} \quad$ for conventional creep

$t_{r}=A_{S P} \cdot F^{-n_{S P}}$

for SPC testing

The stress dependence of the minimum creep rate $\dot{\varepsilon}_{S}$ of the conventional creep test and the load dependence of the minimum deflection rate $\dot{\delta}_{\min }$ of the SPC test can also be described by Norton's law relationship:

$\dot{\varepsilon}_{S}=B_{C R} \cdot \sigma^{m_{C R}}, \quad$ for conventional creep

$\dot{\delta}_{\text {min }}=\mathrm{B}_{\mathrm{SP}} \cdot \mathrm{F}^{\mathrm{m}_{\mathrm{SP}}}$

for SPC testing

Even if the SPC and/or creep tests do not ruptured, it is possible to compare another creep characteristic, namely the rate of stationary (secondary) creep in the steady-state creep region. In general, the lower the secondary creep rate, the longer the time to rupture, and therefore the higher creep resistance under given conditions. The well-known Monkman-Grant equation [9] describes this relationship in the form:

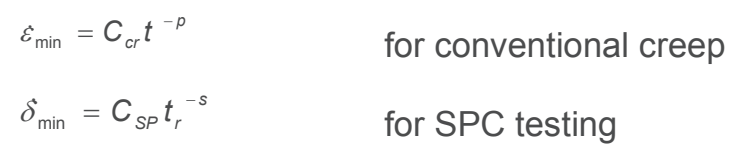

In equations (4) to (9) are $A_{C R}, A_{S P}, n_{C R}, n_{S P}, m_{C R}, m_{S P}, C_{C R}$ and $C_{S P}$ temperature dependent constants.

\section{EXPERIMENTAL MATERIAL}

Chromium modified steel of $\mathrm{F}$ type (X14CrMoVNbN10-1) was developed in the frame of COST 501 Research Programme "Advanced Materials for Power Engineering Components, High Efficiency, Low Emission Systems" as one of the promising steels for rotors and turbines in the ultra-super critical (USC) boilers. The chemical composition of the tested steel produced by SAARSCHMIEDE GmbH Freiformschmiede is shown in Table 1. Heat treatment of the steel was carried out by the regime $1050^{\circ} \mathrm{C} / 6 \mathrm{~h}+1100^{\circ} \mathrm{C} / 6 \mathrm{~h}+570{ }^{\circ} \mathrm{C} / 12.5 \mathrm{~h}$ $+720^{\circ} \mathrm{C} / 24 \mathrm{~h}$.

Table 1 Chemical composition of steel F [mass \%]

\begin{tabular}{|c|c|c|c|c|c|c|c|c|c|c|c|c|}
\hline $\mathbf{C}$ & $\mathbf{M n}$ & $\mathbf{S i}$ & $\mathbf{P}$ & $\mathbf{S}$ & $\mathbf{C r}$ & $\mathbf{N i}$ & $\mathbf{M o}$ & $\mathbf{V}$ & $\mathbf{N b}$ & $\mathbf{N}$ & $\mathbf{B}$ & $\mathbf{A l}$ \\
\hline 0.11 & 0.56 & 0.06 & 0.005 & 0.003 & 10.36 & 0.64 & 1.46 & 0.20 & 0.059 & 0.022 & 0.0079 & 0.009 \\
\hline
\end{tabular}


The extensive testing of the heat resistance of new progressive 9-12\% $\mathrm{Cr}$ steels and their welded joints takes place in the VZÚ Plzeň within the project TE01020068 "Center for Research and Experimental Development of Reliable Energy". Besides the conventional uniaxial creep testing, SPC testing was also performed on the same experimental material: a test block of the weld joint of two progressive modified chromium steels $F$ and FB2 (Figure 3). SPC test specimens were made from the steel F as shown in Figure $\mathbf{3}$ on the right. The test specimen axis was oriented perpendicularly to the surface of the test piece.

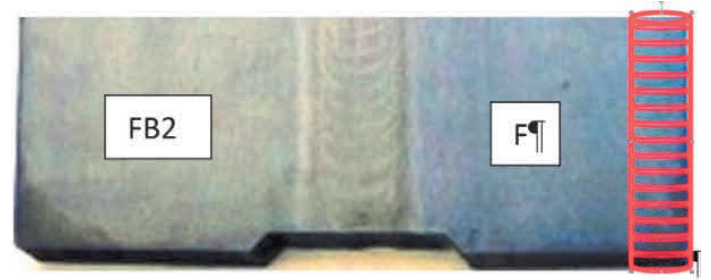

Figure 3 Weldment with test specimens prepared from the steel F

\section{RESULTS OF CREEP AND SPC TESTING}

Uniaxial stress rupture tests of the steel $\mathrm{F}$ were performed at the temperature range from 575 to $650{ }^{\circ} \mathrm{C}$ at stresses ranging from 70 to $220 \mathrm{MPa}$ on single lever-type creep machines in VZU Plzeň. SPC tests (discs of $\varnothing 8 \mathrm{~mm} \times 0.5 \mathrm{~mm}$ ) were tested at two temperatures $\left(625\right.$ and $\left.650{ }^{\circ} \mathrm{C}\right)$ in the load range from 330 to $480 \mathrm{~N}$. SPC tests were performed on a SPUTT 500 testing machine designed and developed in MMV Ostrava under a protective argon atmosphere. Due to the complexity of the stress state in SPC tests, the time to rupture equation for conventional creep and SPCT was used for correlation as described above. The results of the whole testing program are summarized in Table 2.

Table 2 Results of stress rupture and SPC tests of steel F

\begin{tabular}{|c|c|c|c|c|c|c|c|c|c|}
\hline \multicolumn{5}{|c|}{ Stress rupture tests } & \multicolumn{5}{|c|}{ Small punch creep tests } \\
\hline Temperature & Stress & $\begin{array}{l}\text { Time to } \\
\text { rupture }\end{array}$ & Elongation & $\begin{array}{c}\text { Reduction } \\
\text { of area }\end{array}$ & Temperature & Loading & $\begin{array}{l}\text { Time to } \\
\text { rupture }\end{array}$ & Deflection & $\begin{array}{l}\text { Deflection } \\
\text { rate }\end{array}$ \\
\hline${ }^{\circ} \mathrm{C}$ & $\mathrm{MPa}$ & $\mathbf{h}$ & $\%$ & $\%$ & ${ }^{\circ} \mathrm{C}$ & $\mathbf{N}$ & $\mathrm{h}$ & $\mathrm{mm}$ & $\mathrm{mm} \cdot \mathrm{s}^{-1}$ \\
\hline 575 & 200 & 799 & 26.5 & 82.0 & 625 & 480 & 203 & 2.69 & $4.8 \cdot 10^{-07}$ \\
\hline 575 & 220 & 465 & 29.2 & 86.9 & 625 & 450 & 328 & 2.88 & $3.7 \cdot 10^{-07}$ \\
\hline 600 & 120 & 12365 & 16.8 & 78.6 & 625 & 420 & 273 & 2.92 & $3.9 \cdot 10^{-07}$ \\
\hline 600 & 140 & 9888 & 26.0 & 86.0 & 625 & 390 & 1044 & 2.86 & $1.5 \cdot 10^{-07}$ \\
\hline 600 & 180 & 586 & 27.2 & 88.6 & 625 & 360 & 2833 & 2.80 & $3.0 \cdot 10^{-08}$ \\
\hline 625 & 80 & 26133 & 32.5 & 85.0 & 650 & 450 & 70.5 & 2.65 & $1.8 \cdot 10^{-06}$ \\
\hline 625 & 100 & 11621 & 25.8 & 86.9 & 650 & 420 & 68.4 & 2.76 & $1.8 \cdot 10^{-06}$ \\
\hline 625 & 140 & 372 & 23.2 & 88.6 & 650 & 390 & 96.3 & 2.67 & $1.3 \cdot 10^{-06}$ \\
\hline 650 & 70 & 11681 & 18.2 & 72.4 & 650 & 360 & 261 & 2.63 & $4.6 \cdot 10^{-07}$ \\
\hline 650 & 100 & 394 & 33.8 & 90.2 & 650 & 330 & 1503 & 2.50 & $9.7 \cdot 10^{-08}$ \\
\hline
\end{tabular}

The results of stress rupture and SPC tests were mathematically and statistically analyzed by regression analysis and the calculated coefficients of the equations (5), (7) and (9) are stated in Table 3 for both test temperatures 625 and $650^{\circ} \mathrm{C}$, of course, with the exception of the constants of the Monkman-Grant relationship, which is temperature independent. Figure 4 shows the results of this processing for SPC tests of steel $F$ in the form of a logarithmic dependence of time to rupture on the applied load, Figure 5 shows the 
dependence of minimum deflection rate on the applied load, in both cases including the regression line of the respective dependence, in both cases including the regression lines of the respective regression dependence.

Table 3 Coefficients of equations (5), (7) and (9) for steel $\mathrm{F}$ tested at 625 and $650{ }^{\circ} \mathrm{C}$

\begin{tabular}{|c|c|c|c|c|c|c|}
\hline Temperature & Asp & $\mathrm{n}_{\mathrm{SP}}$ & $B_{S P}$ & $\mathrm{~m}_{\mathrm{SP}}$ & $C_{S P}$ & $s$ \\
\hline $625^{\circ} \mathrm{C}$ & 26.50 & 9.82 & -30.67 & 9.14 & \multirow{2}{*}{-3.90} & \multirow{2}{*}{1.01} \\
\hline $650^{\circ} \mathrm{C}$ & 27.68 & 9.82 & -30.63 & 9.46 & & \\
\hline
\end{tabular}

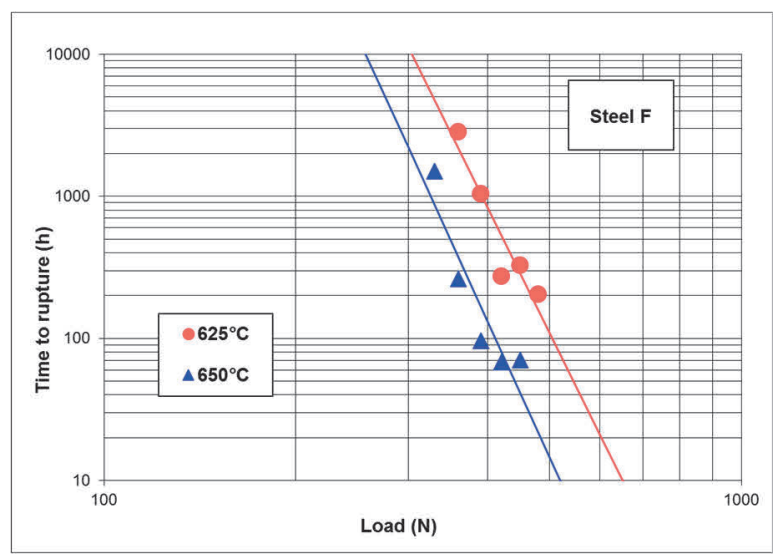

Figure 4 Correlation between loading and time to rupture

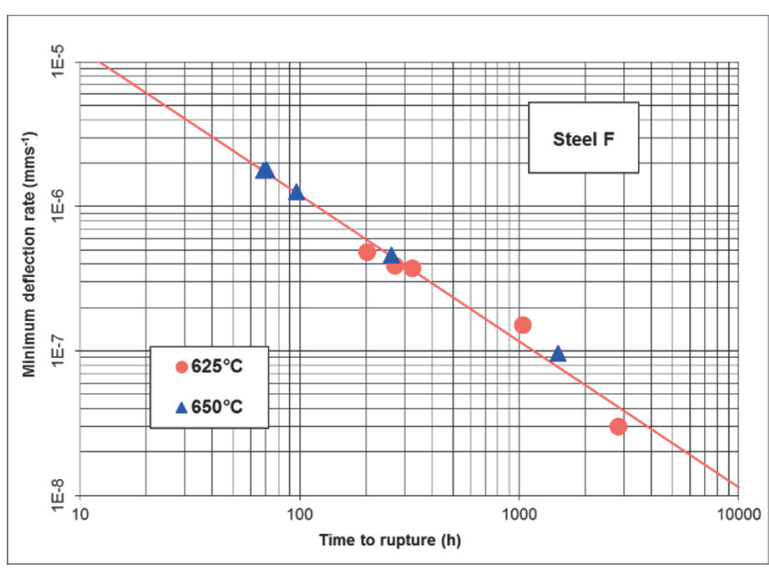

Figure 6 Correlation between time to rupture and minimum deflection rate

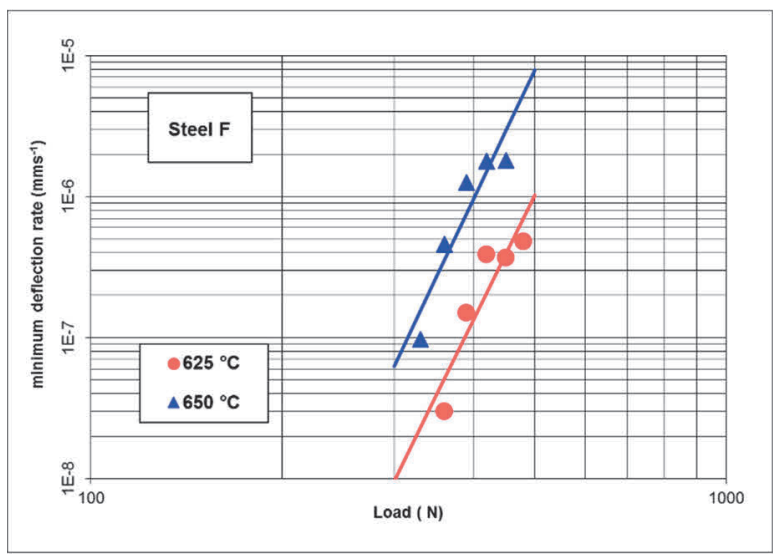

Figure 5 Correlation between loading and minimum deflection rate

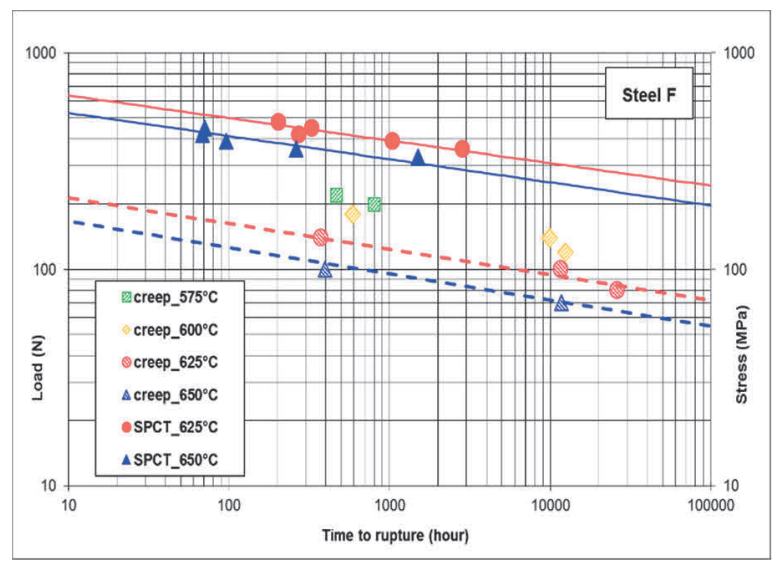

Figure 7 Correlation of the both series of creep and SPC tests of steel F

The data stated in Table 3 and also the graphs clearly show that SPC testing results correspond very well to the assumptions about the similarity of both stress exponents nsp and msp, as is usual in cases when the test conditions correspond to identical creep mechanisms and the same structural state of the material, which can be legitimately expected in the respective case.

The value of exponent $p$ in the original Monkman-Grant equation (8) is positive and greater than or equal to 1 for the majority of materials. If the times to rupture of creep tests are correlated to the corresponding secondary creep rates, all data, regardless of the testing temperature, is found in a straight line with the slope (mathematically expressed by the exponent $p$ ) close to 1 . The same tendency was observed also in the results of SPC tests where the results of all 10 tests lie-in a practically straight line with the slope 1.01 (see Table 3 and Figure 6). 
The benefit of SPC test results lies in their application for estimation of residual life or creep resistance of components after long-term creep exposure in power plants with minimum impact on material sampling and following repair of tested component. In order to be able to perform residual life estimation based on the results of SPC testing, it is necessary to set the constant $\Psi$ according to the above stated equation (3). In the respective case, either stress rupture either SPC tests were performed and, therefore, it was possible to compare both results and to determine the conversion factor $\Psi$. The comparison of results of stress/loadtemperature dependence of the time to rupture of the both types of testing methods $\mathrm{s}$ stress rupture tests with two series of results by using the conversion factor 3.2 is shown in Figure 7 . The conversion factor for the tested steel is 3.2 , which is slightly higher than the factor previously determined in our laboratory on another chromium modified steel P $92(\Psi=2.6)$ [10], as well as in comparison with results obtained by other authors for P91 steel $(\Psi=2.85)[6]$ but it seems to be constant for the whole testing conditions.

\section{CONCLUSION}

Small punch creep tests belong to the promising experimental methods, either thanks to the small amount of test material, which can be even repeatedly sampled from the critical parts, either for the results that correlate very well with the conventional creep tests. Their future then especially lies in the estimation of the residual lifetime of power plant components. It seems that all the relations valid for conventional creep testing, including the Monkman-Grant equation, also apply to the SPC testing.

\section{ACKNOWLEDGEMENTS}

\section{This work was supported by Technology Agency of the Czech Republic (TE01020068 "Center for Research and Experimental Development of Reliable Energy)}

\section{REFERENCES}

[1] LUCAS, G. E. The Development of Small Specimen Mechanical Test Techniques. Journal of Nuclear Materials. 1983, vol. 117, pp. 327-339.

[2] PETZOVÁ, J., BŘEZINA, M., KAPUSŇÁK, M. and KUPČA, L'. Application of Small Punch Testing Methods for Thermal Ageing Monitoring at Primary Circuit Components in Nuclear Power Plant. In ASME 2015 Pressure Vessels and Piping Conference, Vol. 1A: Codes and Standards, Boston: ASME, 2015, paper No. PVP201545539.

[3] KUMAR, J. G. and LAHA, K. Small Punch Creep Deformation and Rupture Behavior of 316L (N) Stainless Steel. Materials Science and Engineering A. 2015. vol. 641, pp. 315-322.

[4] LI, Y. and STURM, R. Small Punch Test for Weld Heat Affected Zones. Mater at High Temp. 2006. vol. 23, no. 34, pp. 225-232.

[5] HURST, R. C., LANCASTER, R. J., NORTON, G., BANIK, R., and BACHE, M. R. A Renaissance in Small Punch Testing at Swansea University. In Baltica IX, Helsinki: VTT Technology, 2013, pp. 538-552.

[6] MILIČKA, K. and DOBEŠ, F. Small Punch Testing of P91 Steel. International Journal of Pressure Vessels and Piping. 2006. vol. 83, pp. 625-634.

[7] CHAKRABARTY, J. A Theory of Stretch Forming over Hemispherical Punch Heads. International Journal of Mechanical Sciences. 1970. vol. 12, no. 4, pp. 315-325.

[8] HOLMSTRÖM, S.. Creep strength and minimum strain rate estimation from Small Punch Creep tests. Materials Science and Engineering: A. 2018. vol. 731, pp. 161-172.

[9] MONKMAN, F.C. and GRANT, N.J. An empirical relationship between rupture life and minimum creep rate in creep-rupture tests. Proc. Am. Soc. Test. Mater. 1956. vol. 56, pp. 593-620.

[10] KUBOŇ, Z. Hodnocení creepových charakteristik ocelí - metody a úskalí. Hutnické listy. 2017. vol. 70, no. 6, pp. 36-40 (in Czech). 